\title{
Predation of Glossiphonia weberi (Blanchard, 1897) on the invasive snail Physella acuta (Draparnaud, 1805) in the presence of an alternative prey
}

\author{
Pranesh Paul, Rupsha Karmakar, Swagata Chatterjee, Ankita Barua, Sampa Banerjee, \\ Gautam Aditya*
}

\begin{abstract}
Department of Zoology, University of Calcutta, 35, Ballygunge Circular Road, Kolkata 700019, India, e-mail: plpranesh@gmail.com (P.P.); rupsha.karmakar94@gmail.com (R.K.); swagata.munna@gmail.com (S.C.); ankitabarua12@gmail.com (A.B.); 03banerjee.sampa@gmail.com (S.B.); gautamaditya2001@gmail.com (G.A. "corresponding author)
\end{abstract}

\begin{abstract}
The North American freshwater snail Physella acuta has invaded and colonized a wide range of freshwater habitats, globally. Resembling other invasive species, $P$. acuta has several negative impacts on the invaded freshwater ecosystems, which calls for its regulation, preferably through biological control. The malacophagous leech Glossiphonia weberi, native to West Bengal, India, had been previously reported as a potential biocontrol agent of $P$. acuta. In this experiment, we observed the predation potential and prey preference of G. weberi on P. acuta in the presence of a native snail, Gyraulus convexiusculus. The results suggest that in all instances, $G$. weberi consumed less $G$. convexiusculus compared to $P$. acuta. In complex habitats, $G$. weberi showed significant prey preference to $P$. acuta except in the habitat characterized by the presence of pebbles. The complex habitats bear a significant $(p<0.05)$ negative impact only in the case of predation on $P$. acuta when present with conspecific but not in heterospecific prey conditions. Therefore, G. weberi qualifies as a useful biological control agent that can affect the colonization and expansion of the invasive snail $P$. acuta, even in the presence of alternative prey.
\end{abstract}

Key words: biological control, invasive species, habitat complexity, native predator, prey preference

\section{Introduction}

The freshwater snail Physella acuta (Draparnaud, 1805) (Gastropoda: Physidae) is native to North America (Dillon 2000) and is now considered to be a globally invasive species (Vinarski 2017). The colonization and establishment of $P$. acuta in different regions in Asia (Ali 1993), Africa (Brown 1980), Australia (Zukowski and Walker 2009) and Europe (Madsen and Frandsen 1989) provide evidence of its geographical range expansion and invasion to the newer habitats. Following the first record from Kolkata (Raut et al. 1995), P. acuta has dispersed, colonized and established in different freshwater habitats of India (Saha et al. 2016; Paul and Aditya 2021). As an invasive species, $P$. acuta survives in a broad range of habitats (Turner and Montgomery 2009), including sewage drains and puddles (Macha 1971; Saha et al. 2016) and agri-horticultural gardens where it causes severe damage to economic plants (Godan 1983). In the sewage systems, they interfere with the purification plants by rendering the biofilters ineffective (Macha 1971). Being a prolific breeder, $P$. acuta has the potential to compete with indigenous snails (Zukowski and Walker 2009) and, therefore, can alter the interactions between the community members. P. acuta can carry several trematode cercaria, consequently, act as an intermediate host of trematode infection of domestic animals and humans (Barragán-Sáenz et al. 2009; Kraus et al. 2014). Considering the negative impacts of $P$. acuta to the ecosystem and human welfare, strategies for controlling $P$. acuta population and range expansion should be implied on an immediate basis. Although, the molluscicides can control the snails to some extent, the primary concern about their use is that the pesticides can kill beneficial organisms such as algae, bacteria, protozoa, worms and many non-target organisms (Hurl- 
bert 1975; Ware 1980). As the toxic compounds result in serious restrictions about their use, it is essential to use alternatives such as biological control to reduce the population of $P$. acuta.

The shells of the freshwater snails are thin and less sculptured compared to marine snail species, which turn them more susceptible to the attack of predators (Vermeij and Covich 1978). The predators of snails can be categorized into two types- shellcrushers and shell-invaders. Many fish, frogs, ducks, geese, certain mammals act as shell crusher predators and are reported to consume on a sufficient number of snails. Cichlid fishes in Africa (Mvogo and Bard 1964) and shell-cracker sunfish in North America (Carothers and Allison 1968) are reported to control vector snails. However, the vertebrates are not satisfactory biological control agents of snails as most of them are general predators of snails and do not threaten the prey species until confined with it. The predatory efficiency of shell-invading marsh fly larva (Diptera: Sciomyzidae), water bugs (Hemiptera: Belostomatidae) and glossiphoniid leeches (Hirudinea: Glossiphoniidae) are well documented (Eckblad 1973; Young and Ironmonger 1980; Raut and Nandi 1985; Aditya and Raut 2002a, b; Aditya and Raut 2005; Paul et al. 2020). Among the native predators, the leech Glossiphonia weberi (Blanchard, 1897) had been proposed as a potential biological control agent of P. acuta (Aditya and Raut 2002a) as it is common in the ponds, lakes and ditches in India (Ghosh 1998). As G. weberi feed on the body fluids of snails and exclusively or predominantly malacophagous (Raut and Nandi 1985), predation on $P$. acuta will mainly depend on how the leech interacts with $P$. acuta on the presence of other native snails. One of the widely distributed native freshwater snails, Gyraulus convexiusculus (Hutton, 1849) (Gastropoda: Planorbidae), is commonly found in ponds, lakes, canals and rice fields of southern Asia (Van Damme 2014). Therefore, G. convexiusculus has been selected as an alternative prey of $G$. weberi in this laboratory experiment.

The interspecific and intraspecific interactions such as competition and predation influence the structure and diversity in the spatiotemporal scale in different communities. The variation in the spatial complexity of habitats results in different predation rates or altered resource exploitation patterns (Schindler et al. 2003; Warfe and Barmuta 2004). Natural aquatic habitats contain macrophytes, pebbles, sand and debris, which add structural complexity in the habitats, otherwise a non-stratified column of water. The structural complexity of habitats helps the prey and the predators to hide or choose attacking positions which ultimately affects the prey-predator interaction (Diehl 1988).
This experiment, therefore, aimed to observe the predation potential of $G$. weberi on the invasive $P$. acuta and native G. convexiusculus when exposed under conspecific and heterospecific conditions. Following this proposition, we investigated how habitat elements like macrophytes and pebbles influence the predation rate and whether $G$. weberi showed any preference for $P$. acuta over $G$. convexiusculus with the intent if $G$. weberi can be used as a prospective biological control agent for invasive snail $P$. acuta. The results of the present study will extend the earlier findings on the ability of G. weberi as predator of exotic snail (Paul et al. 2020). The findings will also be useful in promoting the malacophagous leech in the biological control of the freshwater snails, whether invasive or involved in the disease transmission.

\section{Materials and methods}

\section{Collection and maintenance of the model organisms}

The malacophagous leech G. weberi were collected from the pond located in Ballygunge Science College campus, University of Calcutta $\left(22.5274^{\circ} \mathrm{N}\right.$, $\left.88.3627^{\circ} \mathrm{E}\right)$. They were picked by using soft brushes from submerged decaying leaves and pebbles and brought to the laboratory. The leeches were reared in glass aquaria $(15 \times 15 \times 15 \mathrm{~cm})$ filled with tap water. The leeches were maintained in the rearing density of 25 leeches/ aquarium, and freshwater pulmonate snails were provided as a food source.

The invasive snail $P$. acuta were collected from the sewage drains located in Dunlop, Kolkata $\left(22.6519^{\circ} \mathrm{N}, 88.3786^{\circ} \mathrm{E}\right)$. The snails were observed to be present as attached with the wall of sewage drains, floating plastics and other wastes. The native snail $G$. convexiusculus were collected from the previously mentioned pond, where the snails were observed to be floating freely in surface water, in the submerged decaying leaves and attached with the hydrophytes such as Pistia stratiotes (L.). In both cases, the snails were collected using a sampling net ( $200 \mu \mathrm{m}$ mesh size) and brought to the laboratory. The snails were reared separately in a density of 20 snail/ litre tap water in plastic tubs $(32 \times 26 \times 10$ $\mathrm{cm}$, Tarsons, India) and fed with lettuce ad libitum. The water of rearing aquaria and plastic tubs was changed on a regular basis to remove the unconsumed foods and faecal material.

The specimens used for the experiments were segregated based on the shell height ( $P$. acuta), shell width (G.convexiusculus) and body length (G. weberi) (Fig. 1A-C). The shell height (in mm) or the shell width (in $\mathrm{mm}$ ) was used as a marker for the 
body size of the two snails. The distance between the tip of the apical whorl (apex) to the tip of the last whorl measured along the central axis was considered as shell height for $P$. acuta. The widest dimension of the compressed planisprial shell of $G$. convexiusculus was considered as shell width, measured along the central axis. A snail individual was held in hand, and with the help of a vernier caliper (Insize, Brazil), the shell height (P. acuta) or the shell width ( $G$. convexiusculus) was measured to the nearest $0.1 \mathrm{~mm}$. For the leech, the body length (in $\mathrm{mm}$ from the tip of the anterior to posterior portion, ventral part of the anterior sucker up to the ventral tip of the posterior sucker) was measured when at rest on the glass wall of an aquarium. Initially, a divider was used to measure the length through the glass wall was and checked using a ruler. The tip of the vernier caliper (Insize, Brazil) was placed outside the wall, and the measurement was taken to the nearest $0.1 \mathrm{~mm}$. After measurement, both the leeches and snails were segregated to the desired size classes (based on the body length for the leech and based on shell height/ width for the snails). $G$. weberi belonged to the size class $8-10 \mathrm{~mm}$ (at the resting condition), and $P$. acuta and G. convexiusculus belonged to the size class of $5-7 \mathrm{~mm}$ were considered for the experiment as the collected specimens largely allied to that particular size classes.

\section{Experimental design}

The leech and prey snails were allowed to acclimatize in the laboratory condition for at least seven days before the initiation of experiments. The optimal environment, i.e. temperature 25 $\pm 1^{\circ} \mathrm{C}$, relative humidity -80 to $85 \%$ and $14: 10 \mathrm{~h}$ photoperiod were maintained throughout the rearing and experimental conditions. G. weberi were fed up to satiation with pulmonate snails and kept in starvation for 24 hours before their use in experiments. A single G. weberi was placed in the plastic container $(11 \times 12 \mathrm{~cm}$ with a volume of 2 litres) containing at least 1.5 litres of tap water and was allowed to prey upon $P$. acuta and $G$. convexiusculus offered in a ratio of 10:0 (conspecific condition for P. acuta), 0:10 (conspecific condition for G. convexiusculus) and 5:5 (heterospecific condition for both prey snails). To find out the effect of habitat complexity on the predation rate of $G$. weberi, we considered four types of habitat: a). Open (O): This habitat contained only tap water and without any pebbles or macrophytes.

b). Macrophyte complexity (M): Five tape grass (Vallisneria spiralis) leaves were provided vertically to the water surface in each of the experimental containers. c). Pebbles complexity (P): Different sizes of pebbles $(5-15 \mathrm{~mm})$ were mixed and distributed evenly in the base of tap water containing plastic containers.

d). Macrophyte and pebbles complexity (MP): The pebbles were added as a monolayer along with $V$. spiralis leaves placed vertically with the water surface to create a comparatively more complex habitat.

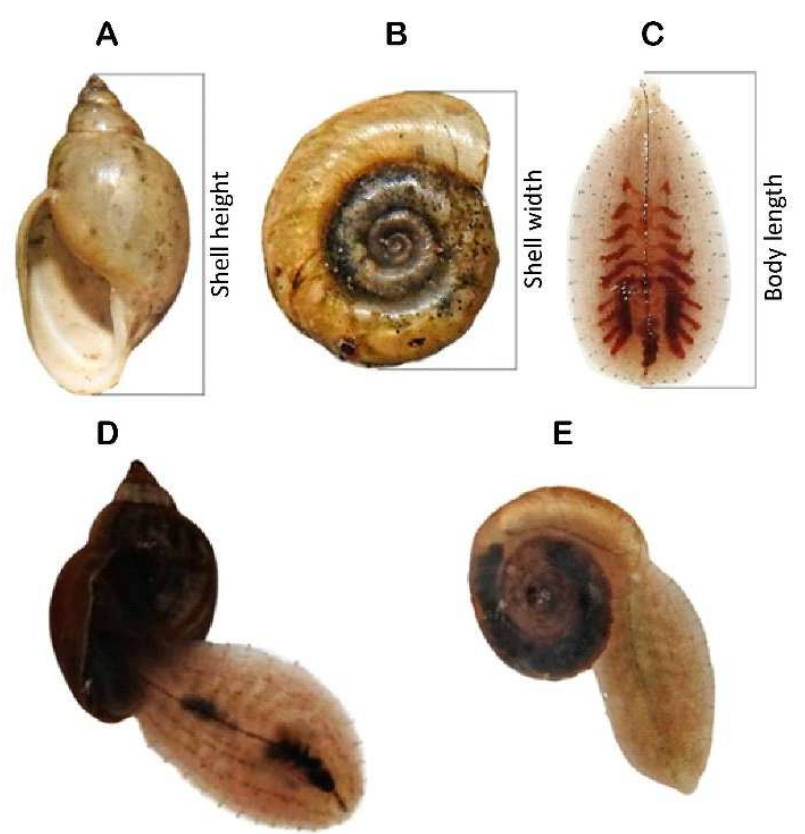

Fig. 1. The model organisms used in the experiment:

A - P. acuta, B - G. convexiusculus and C - G. weberi, and their measurements using shell height, width and body length respectively. Predation of $G$. weberi on: D - P. acuta, and $\mathrm{E}-$ G. convexiusculus

Each combination of experiments was replicated at least 40 times. The number of prey snails consumed by $G$. weberi was noted every 24 hours. At the end of 24 hours, all organisms were replaced in such a way that $P$. acuta, G. convexiusculus and $G$. weberi were used only once in the trials.

\section{Data analysis}

The numbers of prey consumed per 24 hours in each combination were subjected to descriptive analysis. To determine whether the consumption of prey snails differed significantly due to complex habitats or prey heterogeneity, analysis of variance (ANOVA) and Fisher's LSD test was applied (Zar 1999). To ascertain if the predator showed any relative prey preference or avoidance, the number of $P$. acuta and $G$. convexiusculus consumed by $G$. weberi were analyzed for the index of selectivity (Manly 1974; Chesson 1978). The equation used to calculate the selectivity index is: 


$$
\alpha_{i}=\frac{c_{i}}{n_{i}} / \sum_{1}^{n} \frac{c_{j}}{n_{j}}
$$

where: $\alpha_{i}=$ selectivity index for P. acuta or G. convexiusculus, $c_{i}=$ number of $P$. acuta or $G$. convexiusculus consumed, $n_{i}=$ abundance of $P$. acuta or $G$. convexiusculus, $c_{\mathcal{F}}=$ total number of prey consumed and $n_{f}=$ abundance of total prey in the experimental setup. The final values of selectivity $\left(S_{i}\right)$ were standardised between the ranges $0-1$ by dividing $\alpha_{i}$ of one prey species with the sum of the $\alpha_{i}$ of two prey (Manly 1974; Rehage et al. 2005):

$$
S_{i}=\alpha_{i} / \sum \alpha_{i}
$$

As two prey species were present in the experimental setup, values of $S_{i}$ greater than 0.5 indicate relative preference and lower than 0.5 indicate relative avoidance by the predator. A onesample t-test was applied to determine if the $S_{i}$ differs significantly from 0.5 . The effect of complex habitat was determined using $K$, a constant that measures the effect of habitat complexity on the predation rate. The equation to calculate $K$ is: $C_{o}=K \cdot C_{c h}$, where: $C_{o}$ is the number of prey consumed in open habitat, and $C_{c h}$ is the number of prey consumed in complex habitat. The value of $K>1$ indicates the negative impact on predation rate by the complex habitat. The calculated values of $K$ in different habitats $\left(K_{m}\right.$ - in presence of macrophytes; $K_{p}$ in presence of pebbles and $K_{m p}$ - in presence of both macrophytes and pebbles) were further analysed using a one-way t-test at 0.05 level to determine if the effect of complex habitat was statistically significant. ANOVA and onesample t-test were analyzed by a licensed copy of XLSTAT version 2010.04.02 (Addinsoft 2010).

\section{Results}

The prey snails, $P$. acuta and $G$. convexiusculus, were consumed by the malacophagous leech G. weberi (Fig. 1D-E) in comparable numbers, with prominent variations due to the habitat condition and the prey combinations (Fig. 2). In the conspecific conditions, the consumption of the snail $P$. acuta was $1.31 \pm 0.16$ (Mean $\pm \mathrm{SE})$, while under the heterospecific condition, the consumption was $0.61 \pm 0.08$ per 24 hours. Similarly, the consumption of the snail G. convexiusculus under conspecific conditions was $0.69 \pm 0.11$ and under heterospecific conditions was $0.38 \pm 0.09$ per 24 hours. Nonetheless, the leech G. weberi consumed significant numbers of each prey type with significant variations observed for the habitat type differences and the prey combinations substantiated through ANOVA (Table 1).

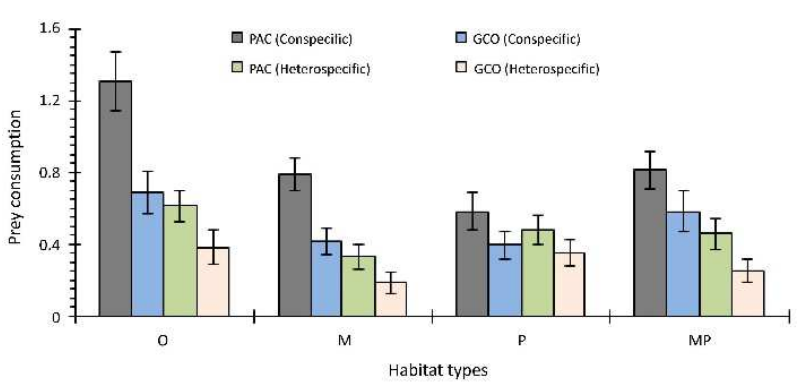

Fig. 2. Comparative prey consumption (Mean \pm SE) by G. weberi in the conspecific and heterospecific conditions of prey snails (PAC - P. acuta and GCO - G. convexiusculus) under different habitat types per 24 hours

Table 1. The results of ANOVA representing the effects of the habitat types and the prey (PAC $-P$. acuta and GCO $-G$. convexiusculus) heterogeneity on the prey consumption by $G$. weberi. Values in bold indicate significant differences at least

\begin{tabular}{|c|c|c|c|c|c|}
\hline & Source & SS & $\mathrm{DF}$ & MS & $\mathrm{F}$ \\
\hline \multirow{5}{*}{ 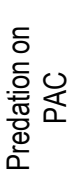 } & Habitat & 8.686 & 3 & 2.895 & 6.466 \\
\hline & Prey combination & 12.144 & 1 & 12.144 & 27.120 \\
\hline & Habitat*Prey combination & 3.769 & 3 & 1.256 & 2.806 \\
\hline & Error & 160.309 & 358 & 0.448 & \\
\hline & Total & 183.956 & 365 & & \\
\hline \multirow{5}{*}{ 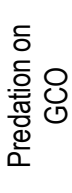 } & Habitat & 1.397 & 3 & 0.466 & 1.418 \\
\hline & Prey combination & 3.098 & 1 & 3.098 & 9.432 \\
\hline & Habitat*Prey combination & 1.629 & 3 & 0.543 & 1.653 \\
\hline & Error & 117.245 & 357 & 0.328 & \\
\hline & Total & 123.178 & 364 & & \\
\hline
\end{tabular}
at the $p<0.05$ level

The vulnerability of the snails to the leech varied with the habitat conditions, with the open habitat conditions favoured the predation by the leech. On a comparative scale, the presence of the habitat elements of complex conditions favoured the snail $P$. acuta, with the least predation by the leech, reflected through the prey consumption pattern. However, no significant effect of complex habitats on the consumption of $G$. convexiusculus was observed. The results of ANOVA indicated that the heterogeneity of prey species had a significant effect on the predation rate on both snails (Table 1). The pattern of the prey selection under the varied habitat conditions is reflected through the prey selectivity index of the leech. Although the total prey consumption varied with the habitat types, the significant preference for the snail $P$. acuta was observed for the habitats- $O, M$ and $M P$ (Table 2 ), substantiated through a one-sample t-test.

A comparison of the $K$ value for the effects of the habitat conditions on the predation ability of the leech was further constructed (Fig. 3). The negative effects were found to be significant for 
$P$. acuta in conspecific conditions, but no significant effect in the case of $P$. acuta in heterospecific conditions and G. convexiusculus was observed.
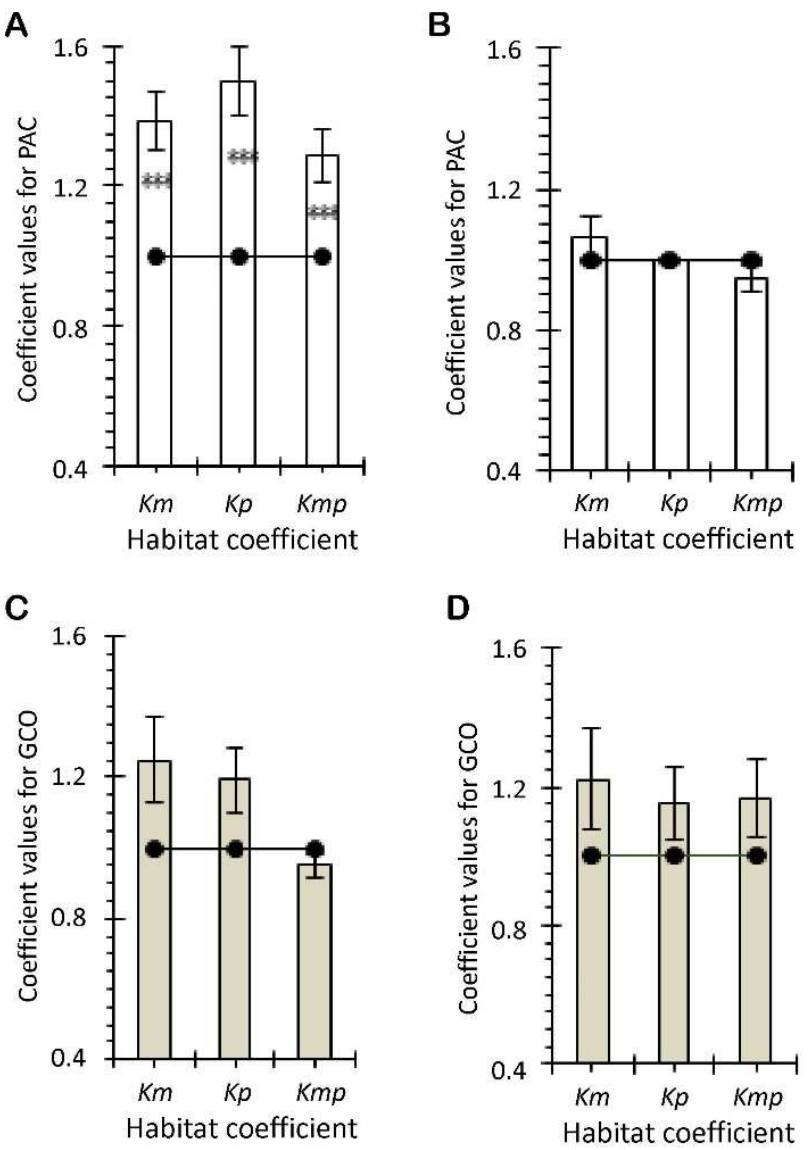

Fig. 3. The constant ' $K$ ' represents the effects of habitat complexity on the predation rate of $G$. weberi against the open space as a control habitat. The $K m, K p$, and $K m p$ are the effects of macrophyte, pebbles and both macrophyte and pebbles complexity, respectively. The graphs represent the effects of habitat complexity on the predation rate upon $P$. acuta (PAC) [A - conspecific, and B - heterospecific condition] and G. convexiusculus (GCO) [C - conspecific, and D - heterospecific condition]. The horizontal line indicates the null hypothesis of equal predation in open and respective complex habitats. The ${ }^{* * *}$ represents that the values are significantly higher than 1 at least at $p<0.001$ level

Table 2. Values of the coefficient of selectivity exhibited by $G$. weberi against $P$. acuta (PAC) and G. convexiusculus (GCO) observed in the laboratory under different habitat complexities. The $p$-values in bold indicate significant preference of $G$. weberi for $P$. acuta

\begin{tabular}{lccc}
\hline \multirow{2}{*}{ Habitat type } & \multicolumn{2}{c}{ Selectivity $($ Si) } & \multirow{2}{*}{-value } \\
\cline { 2 - 3 } & PAC & GCO & \\
\hline Open & 0.71 & 0.29 & $<\mathbf{0 . 0 0 0 1}$ \\
Macrophyte (M) & 0.67 & 0.33 & $\mathbf{0 . 0 2}$ \\
Pebbles (P) & 0.58 & 0.42 & 0.18 \\
MP & 0.63 & 0.37 & $\mathbf{0 . 0 4}$ \\
\hline
\end{tabular}

\section{Discussion}

Successful colonization and establishment of nonnative organisms depend on several direct or indirect factors such as life-history traits, interspecific interactions with native organisms, and greater environmental tolerance (Sakai et al. 2001; Cieplok and Spyra 2020). Sometimes, the social, economic and anthropogenic reasons are as crucial as biological factors for the establishment of non-native species. For instance, with the increasing popularity of aquarium pets, more than 150 aquatic species linked with aquarium trades have invaded the natural ecosystems (Chang et al. 2009). The dispersal and establishment of $P$. acuta, perhaps, resulted from such aquarium trade (Duggan 2010). In the invaded ecosystems, the presence of native predators often resist non-native prey invasion by high consumption (de Rivera et al. 2005; Cheng and Hovel 2010). Alternatively, avoidance or low predation on non-native prey by native predators results in the proliferation of non-native prey populations (Shwartz et al. 2009). Therefore, the colonization chances of non-native species can be reduced if the predatory pattern exhibits a preference for the non-native species. Insect predators such as Sphaerodema rusticum and Sepedon scapularis larva were proved to be useful biological control agents against invasive snail $P$. acuta and other indigenous snails (Aditya and Raut 2001; Aditya and Raut 2002b; Maharaj et al. 1992). Aside from insect predators, empirical studies showed that many native leech predators preyed upon a significant number of invading snail species. The leech, G. weberi, was reported as a potential biological control agent against invasive $P$. acuta and exotic snails such as Planorbarius corneus and Pomacea bridgesii in India (Aditya and Raut 2002a; Aditya and Raut 2005; Paul et al. 2020). However, the prey preference of predator is an essential factor for the successful regulation of invasive snails. Since the predatory $G$. weberi is linked with the indigenous prey snails, a comparative evaluation of the prey preference is imperative to understand the potential in regulating the invasive prey snails. In similar studies, where indigenous planorbids and invasive physid snails were present as prey, sciomyzid predators killed significantly higher planorbids than the physid snails (Maharaj et al. 1992; Appleton et al. 1993). However, in this experiment, G. weberi consumed significantly more $P$. acuta than $G$. convexiusculus in all complex habitats and prey combinations. Possibly, owing to the differences in shape and structure of the shells, the approach of $G$. weberi for the catch, hold, and subsequent penetration inside the shell varied between $P$. acuta and G. convexiusculus. In open (O), macro- 
phyte (M) and macrophytes and pebble (MP) habitats, $G$. weberi significantly preferred $P$. acuta over G. convexiusculus. The physid snails have the ability to recognize the potential danger of predatory leeches and show a few types of avoidance response (Wilken and Appleton 1990; Brönmark and Malmqvist 1986), such as avoiding slow-moving predators by retracting the body into the shell, floating or by shaking their shell vigorously either remained attached to the substratum or while floating on the surface (Bronmark and Malmqvist 1986). They show the shell twisting or shaking behaviour with the help of the physid muscle "sensu stricto" and fan muscles, which are unique to the Physidae family (Naranjo-Garcia and Appleton 2009). Despite the escaping capability from predators, in this experiment, the predation on $P$. acuta is higher, possibly because of differences in the shell shapes, their larger aperture size and exposed foot than G. convexiusculus.

One of the fundamental characteristics of habitat is habitat complexity, i.e. the arrangement of habitat elements in different habitat spaces (Bell et al. 1991). Habitat complexity plays an essential role in the prey-predator interaction by altering the predation rate. A negative effect on predation rate can occur when prey finds a new place to a refuge or by the alternation of prey detection and predator encounter rate with increasing habitat complexity (Persson and Eklöv 1995; Warfe and Barmuta 2004). Similarly, the increasing complexity can affect the prey survival either by blocking their movement or reducing predator detection ability (Rilov et al. 2007). In the present study, no significant change in predation rate on $G$. convexiusculus was observed in both conspecific and heterospecific conditions with increasing habitat complexity. This result indicates that G. convexiusculus gained no benefit from habitat complexity as the consumption rate remained more or less similar to the open habitat. Contrarily, the predation rate on $P$. acuta has been significantly reduced in all types of complex habitats only when present in the conspecific condition. Nevertheless, when P.acuta were present with G. convexiusculus, no significant difference in predation rate on $P$. acuta was observed in complex habitats compared to open habitat. Besides the structural complexity of habitats, the conspecific and heterospecific presence of prey species also influenced the predation rate of $G$. weberi. Despite the structural complexity and prey heterogeneity resulted in reduced predation on $P$. acuta in some conditions, in all habitats, predation on $P$. acuta remained higher than $G$. convexiusculus, and $G$. weberi preferred $P$. acuta over $G$. convexiusculus (except $P$ habitat). In a similar experiment, $G$. weberi consumed higher number of an indigenous snail, Indoplanorbis exustus, in the habitat characterized with the presence of pebbles (Paul et al. 2020). Perhaps, the movement of the planospiral shelled $G$. convexiusculus and I. exustus are affected due to the pebbles which may have eased the prey capture by the leeches. Nonetheless, G. weberi did not consume significantly higher number of $G$. convexiusculus than $P$. acuta, even in the background of pebbles, suggesting that the conispiral $P$. acuta are more preferred prey. As stated in the "exotic prey naivete hypothesis", non-native species can suffer higher predation pressure from the native predators than the native prey species (Li et al. 2011), which may provide biotic resistance against the establishment of non-native species in newer habitats. The hypothesis can be sustained through the observation that G. weberi preferred an exotic snail, P. corneus, over a native snail, $I$. exustus, under different complex habitats (Paul et al. 2020) and as observed for $P$. acuta in this experiment. Hence, the novelty of invasive or exotic prey does not seem problematic for $G$. weberi as it readily consumed and preferred the non-native prey species over alternative indigenous prey. Therefore, it was apparent that the malacophagous leech $G$. weberi can impart a regulatory effect on the colonization and establishment of the invasive snail $P$. acuta in the natural habitats. Further studies may be carried out to decipher the extent of predation in the presence of multiple prey snails.

\section{Acknowledgement}

The critical comments of the anonymous reviewer that enabled enhancement of the manuscript to its present form are duly acknowledged. The authors are grateful to the Head, Department of Zoology, University of Calcutta, Kolkata, West Bengal, India, for the facilities provided. P.P. acknowledges the financial support of CSIR-HRDG [09/028(1115)/ 2019-EMR-1, dated 06/08/2019].

\section{References}

Addinsoft SARL., 2010, XLSTAT softwere, version 9.0. Paris: Addinsoft.

Aditya G., Raut S.K., 2001, Predation of water bug Sphaerodema rusticum Fabricius on the snail Pomacea bridgesi (Reeve), introduced in India, Curr. Sci. 81:1413-1414.

Aditya G., Raut S.K., 2002a, Potential of the leech Glossiphonia weberi (Blanchard) in controlling the sewage snail Physa acuta Draparnaud, Curr. Sci. 83(11): 1317-1319. 
Aditya G., Raut S.K., 2002b, Predation potential of the water bugs Sphaerodema rusticum on the sewage snails Physella acuta, Mem. Inst. Oswaldo Cruz. 97(4): 531-534.

Aditya G., Raut S.K., 2005, Feeding of the leech Glossiphonia weberi on the introduced snail Pomacea bridgesii in India, Aquat. Ecol. 39: 465-471.

Ali J.H., 1993, The distribution of Physella acuta Draparnaud (Gastropoda: Physidae) in Malaysia and its suitability as test material for insecticide toxicity studies, J. Med. Appl. Malacol. 5: 129-134.

Appleton C.C., Miller R.M., Maharaj R., 1993, Control of schistosomiasis host snails in South Africa - the case for biocontrol by predator augmentation using sciomyzid flies. J. Med. Appl. Malacol. 5: 107-116.

Barragán-Sáenz F.A., Sánchez P., Hernandez-Gallegos O., Salgado-Maldonado G., 2009, Larval stages of trematodes in gastropods from Lake Chicnahuapan, State of Mexico, Mexico, Parasitol. Res. 105: 11631167.

Bell S., McCoy E., Mushinsky H., 1991, Habitat structure: the physical arrangement of objects in space, Chapman \& Hall: 3-27.

Brönmark C., Malmqvist B., 1986, Interactions between the leech Glossiphonia complanata and its gastropod prey, Oecologia. 69: 268-276.

Brown D.S., 1980, Freshwater Molluscs of Africa and their Medical Importance, Taylor and Francis, London, p. 487.

Carothers J.L., Allison R., 1968, Control of snails by the redear (shellcracker) sunfish, FAO Fisheries Report. 44(5): 399-406.

Cieplok A., Spyra A., 2020, The roles of spatial and environmental variables in the appearance of a globally invasive Physa acuta in water bodies created due to human activity, Sci. Total Environ. 744: 140928.

Chang A.L., Grossman J.D., Spezio T.S., Weiskel H.W., Blum J.C., Burt J.W., Muir A.A., Piovia-Scott J., Veblen K.E., Grosholz E.D., 2009, Tackling aquatic invasions: risks and opportunities for the aquarium fish industry, Biol. Invasions. 11: 773-785.

Cheng B.S., Hovel K.A., 2010, Biotic resistance to invasion along an estuarine gradient, Oecologia. 164(4): 1049-59.

Chesson J., 1978, Measuring Preference in Selective Predation, Ecology. 59(2): 211-215.

de Rivera C., Ruiz G., Hines A., Jivoff P., 2005, Biotic resistance to invasion: Native predator limits abundance and distribution of an introduced crab, Ecology. 86: 3364-3376.

Diehl S., 1988, Foraging efficiency of three freshwater fishes: effects of structural complexity and light, Oikos. 53: 207-214.

Dillon R.T., 2000, The ecology of freshwater mollusks, Cambridge University Press, New York.

Duggan I.C., 2010, The freshwater aquarium trade as a vector for incidental invertebrate fauna, Biol. Invasions. 12: 3757-3770.

Eckblad J.W., 1973, Experimental predation studies of malacophagous larvae of Sepedon fuscipennis (Diptera: Sciomyzidae) and aquatic snails, Exp. Parasitol. 33(2): 331-342.

Ghosh G.C., 1998, Annelida: Hirudinea, p. 277-249.
Godan D., 1983, Pest snails and slugs, Springer-Verlag, Berlin, p. 445.

Hurlbert S.H., 1975, Secondary effects of pesticides on aquatic ecosystems, [in:] Gunther F.A., (ed) Residue Reviews. Residue Reviews, Springer, New York.

Kraus T., Brant S., Adema C., 2014, Characterization of Trematode Cercariae from Physella acuta in the Middle Rio Grande, Com. Parasitol. 8: 105-109.

Manly B.F.J., 1974, A model for certain types of selection experiments. Biometrics. 30 (2): 281-294.

Li Y., Ke Z., Wang S., Smith G.R., Liu X., 2011, An exotic species is the favorite prey of a native enemy, PLoS ONE 6(9): e24299.

Macha S., 1971, Kulture influsse auf die Mollusken fauna, Tschech Casop Acta Musci Silesiae, Ser A, Sci. Nat. 20: 121-146.

Madsen H., Frandsen F., 1989, The spread of fresh water snails including those of medical and veterinary importance, Acta Trop. 46: 139-149.

Maharaj R., Appleton C.C., Miller R.M., 1992, Snail predation by larvae of Sepedon scapularis Adams (Diptera: Sciomyzidae), a potential biocontrol agent of snail intermediate hosts of schistosomiasis in South Africa, Med. Vet. Entomol. 6(3): 183-187.

Mvogo L., Bard J., 1964, Seconde note d'infonnation sur l'Astatoreochromis alluaudi, Poisson malacophage utilisable dans la prophylaxie de la bilharziose, Bull. Soc. Pathol. Exot. 57: 21-23.

Naranjo-García E., Appleton C.C., 2009, The architecture of the physid musculature of Physa acuta Draparnaud, 1805 (Gastropoda: Physidae), Afr. Invertebr. 50(1): 1-11.

Paul P., Aditya G., 2021, Invasion of the freshwater snail Physella acuta (Draparnaud, 1805) in selected ponds of North Dinajpur, India. J. Environ. Biol. 42(3): 577581.

Paul P., Karmakar R., Aditya G., 2020, Choosing exotic over the familiar taste: habitat-specific preferences of a malacophagous leech for freshwater snails as prey, Euro. J. Ecol. 6(1): 121-136.

Persson L., Eklöv P., 1995, Prey refuges affecting interactions between piscivorous perch and juvenile perch and roach, Ecology. 76: 70-81.

Raut S.K., Bhaumik S., Das S., 1995, Occurrence of the snail Physa acuta Draparnaud in Calcutta, India, J. Bombay Nat. Hist. Soc. 92: 434.

Raut S.K., Nandi N.C., 1985, The leech Glossiphonia weberi in the control of the snails Lymnaea luteola, a predator-prey interaction. Environment and Ecology. 3: 21-24.

Rehage J.S., Barnett B.K., Sih A., 2005, Foraging behavior and invasiveness: do invasive Gambusia exhibit higher feeding rates and broader diets than their noninvasive relatives? Ecol. Freshwat. Fish. 14: 352360.

Rilov G., Figueira W.F., Lyman S.J., Crowder L.B., 2007, Complex habitats may not always benefit prey: linking visual field with reef fish behavior and distribution, Mar. Ecol. Prog. Ser. 329: 225-238.

Saha C., Pramanik S., Chakraborty J., Parveen S., Aditya G., 2016, Abundance and body size of the invasive snail Physa acuta occurring in Burdwan, West Bengal, India, J. Entomol. Zool. Stud. 4: 490-497. 
Sakai A.K., Allendorf F.W., Holt J.S., Lodge D.M., Molofsky J., With K.A., Baughman S., Cabin R.J., Cohen J.E., Ellstrand N.C., Mccauley D.E., O'neil P., Parker I.M., Thompson J.N., Weller S.G., 2001, The Population Biology of Invasive Species, Annu. Rev. Ecol. Evol. 32: 305-332.

Schindler M., Fesl C., Chovanec A., 2003, Dragonfly associations (Insecta: Odonata) in relation to habitat variables: a multivariate approach, Hydrobiologia. 497: 169-180.

Shwartz A., Strubbe D., Butler C.J., Matthysen E., Kark S., 2009, The effect of enemy-release and climate conditions on invasive birds: a regional test using the rose-ringed parakeet (Psittacula krameri) as a case study, Divers. Distrib. 15: 310-318.

Turner A.M., Montgomery S.L., 2009, Hydroperiod, predators and the distribution of physid snails across the freshwater habitat gradient, Freshw. Biol. 54: 1189-1201.

Van Damme D., 2014, Gyraulus convexiusculus, The IUCN Red List of Threatened Species, https:// dx.doi.org/10.2305/IUCN.UK.20141.RLTS.T166681 A42 421590.en.

Vermeji G.J., Covich A.P., 1978, Coevolution of freshwater gastropods and their predators, Am. Nat. 112(987): 833-843.
Vinarski M., 2017, The history of an invasion: phases of the explosive spread of the physid snail Physella acuta through Europe, Transcaucasia and Central Asia, Biol. Invasions. 19(4): 1299-1314.

Ware G.W., 1980, Effects of pesticides on non target organisms, [in:] Gunther F.A., Gunther J.D., (eds,) Residue Reviews. Springer, New York.

Warfe D.M., Barmuta L.A., 2004, Habitat structural complexity mediates the foraging success of multiple predator species, Oecologia, 141: 171-178.

Wilken G.B., Appleton C.C., 1990, Avoidance responses of some indigenous and exotic freshwater pulmonate snails to leech predation in South Africa, S. A. J. Zool. 26(1): 6-10.

Young J.O., Ironmonger J.W., 1980, A laboratory study of the food of three species of leeches occurring in British lakes, Hydrobiologia. 68: 209-215.

Zar J.H., 1999, Biostatistical analysis. Pearson Education India Singapore Pvt. Ltd., Indian Branch, p. 663.

Zukowski S., Walker K., 2009, Freshwater snails in competition: Alien Physella acuta (Physidae) and native Glyptophysa gibbosa (Planorbidae) in the River Murray, South Australia, Mar. Freshwat. Res. 60: 9991005. 